Check for updates

Cite this: RSC Adv., 2017, 7, 55371

Received 6th October 2017

Accepted 28th November 2017

DOI: 10.1039/c7ra11018a

rsc.li/rsc-advances

\title{
Aromatic poly(ether ether ketone)s capable of crosslinking via UV irradiation to improve gas separation performance
}

\author{
María Puertas-Bartolomé, ${ }^{a}$ Michelle E. Dose, ${ }^{b}$ Paula Bosch, ${ }^{a}$ Benny D. Freeman, ${ }^{b}{ }^{b}$ \\ James E. McGrath, ${ }^{c}$ Judy S. Riffle, ${ }^{c}$ Angel E. Lozano, ${ }^{\text {ade }}$ José G. de la Campa (D) ${ }^{a}$ \\ and Cristina Álvarez (D) *a
}

\begin{abstract}
The effect of UV-crosslinking on the gas transport properties of two poly(ether ether ketone)s derived from difluorobenzophenone and two bisphenol derivatives, with four (TMBP-DFB) or six (HMBP-DFB) methyl groups, has been studied. The crosslinking reaction was conducted on dense membranes, using polychromatic light, with wavelengths higher than $350 \mathrm{~nm}$, at room temperature and in presence of air. Both polymers were able to produce crosslinked membranes, with gel fractions close to $75 \%$, but a shorter irradiation time was required for HMBP-DFB. A DFT quantum mechanical study has stated that HMBP-DFB radical formation is much easier than for TMBP-DFB, which would support the fastest kinetics of the crosslinking process for HMBP-DFB. The crosslinked membranes have shown greatly improved gas transport properties, especially for the $\mathrm{O}_{2} / \mathrm{N}_{2}$ gas pair, where the Robeson upper bound line of 1991 was clearly surpassed. The improvement in selectivity has been ascribed to the better molecular-sieving characteristics of crosslinked membranes.
\end{abstract}

\section{Introduction}

Permeability and selectivity are the two important parameters that determine the characteristics of a gas separation membrane. ${ }^{1}$ Polymer membranes must have good separation capacity for a particular gas in a mixture and high permeability, as well as good mechanical properties and high thermal stability. ${ }^{2,3}$ However, conventional polymer membranes suffer from a well-known trade-off between these two parameters, because as the permeability of polymers increases, their ability to differentiate between gases decreases. This behaviour was first evidenced by Robeson in 1991 and then updated in 2008, showing the progress achieved in the gas separation field. ${ }^{4-7}$

Glassy aromatic polymers, such as polyimides and polysulfones, are very commonly employed for gas separation membranes because they offer high selectivity and good mechanical properties. Based on the solution-diffusion mechanism, the more permeable gases are those with small molecular

\footnotetext{
${ }^{a}$ Institute of Polymer Science and Technology, Consejo Superior de Investigaciones Cientificas, ICTP-CSIC, Juan de la Cierva 3, 28006 Madrid, Spain. E-mail: cristina. alvarez@ictp.csic.es

${ }^{b}$ The University of Texas at Austin, Department of Chemical Engineering, Center for Energy and Environmental Resources, 10100 Burnet Road, Building 133, Austin, TX 78758, USA

${ }^{c}$ Macromolecules and Interfaces Institute and Department of Chemistry, Virginia Tech, Blacksburg, VA 24061, USA

${ }^{a}$ SMAP, UA UVa-CSIC, University of Valladolid, Paseo Belen 7, 47011 Valladolid, Spain 'IU CINQUIMA, University of Valladolid, Paseo Belen 7, 47011 Valladolid, Spain
}

diameter and selectivity is mainly controlled by size based diffusion rate differences. Furthermore, it has been assumed that local to short scale cooperative segmental motions, which take place in glassy state, are responsible for the opening of the channels that connect free volume elements and then allow the passage of the gas molecules through the membrane. ${ }^{8}$ Therefore, glassy polymers have limited size-selectivity for practical applications because there is a wide size distribution of free volume elements (holes) and, moreover, the holes fluctuate in size due to the thermal motions of the polymer chains. In this context, the most effective way of improving permeability/ selectivity properties is to create polymer structures with very high stiffness, while simultaneously frustrating interchain packing in order to improve permeability. ${ }^{9}$

Crosslinking induced by ultraviolet (UV) irradiation is a simple route to modify the structure of dense membranes by the formation of a network, which increases the rigidity. One of the first indications that UV crosslinking could improve the environmental stability and the performance of gas separation membranes of polyimides was reported in the patent literature. ${ }^{10}$ Since then, other studies have shown the effect of UV irradiation on gas transport properties of benzophenone containing polyimides, ${ }^{11}$ poliarylates ${ }^{12}$ polyarylene ethers, ${ }^{13}$ poly(imide-siloxane) segmented copolymers ${ }^{14}$ ketone containing poly(2,6-dimethylphenylene oxide) copolymers $^{15}$ and poly(2,6-dimethylphenylene oxide) and poly(arylene ether ketone) blends. ${ }^{16}$ In general, the most notable improvements in membrane performance have been achieved in $\mathrm{H}_{2} / \mathrm{CH}_{4}, \mathrm{O}_{2} / \mathrm{N}_{2}$, 
or $\mathrm{CO}_{2} / \mathrm{CH}_{4}$ separations due to an enhancement in the sizesieving capability of the membranes. Besides, the method is useful to improve the membrane stability and to reduce undesirable phenomena, such as physical aging ${ }^{17}$ and plasticization $^{\mathbf{1 8}}$, which have a crucial impact on membrane durability. ${ }^{11,19,20}$

This work examines the effect of UV irradiation on the gas transport properties of two glassy amorphous poly(ether ether ketone)s (PEEKs) films based on difluorobenzophenone (DFB) and $3,3^{\prime}, 5,5^{\prime}$-tetramethyl-4, $4^{\prime}$-dihydroxybiphenyl (TMBP) or $2,2^{\prime}, 3,3^{\prime}, 5,5^{\prime}$-hexamethyl-4, $4^{\prime}$-dihydroxybiphenyl (HMBP). The monomers derived from bisphenol were chosen because the methyl groups reduce the efficiency of polymer chain packing, thereby increasing gas permeability and, moreover, they provide an abundant source of benzylic methyl groups for crosslinking reactions. UV light was used to excite the benzophenone moiety that subsequently abstracts a hydrogen radical from a benzylic methyl group. The two radicals created are combined to form a covalent bond, thus causing crosslinking. A DFT quantum mechanical study has been performed in order to estimate the ability of formation of radicals from methylene groups. The improvement in the size-sieving capability and gas selectivity of the dense membranes, as a function of the irradiation time, has been also examined.

\section{Experimental}

\section{Materials}

$3,3^{\prime}, 5,5^{\prime}$-tetramethyl-4, $4^{\prime}$-dihydroxybiphenyl (TMBP) and $2,2^{\prime}, 3,3^{\prime}, 5,5^{\prime}$-hexamethyl-4, $4^{\prime}$-dihydroxybiphenyl (HMBP) were purchased from Akron Polymer Systems and purified by sublimation at $200{ }^{\circ} \mathrm{C}$ before use. $4,4^{\prime}$-Difluorobenzophenone (DFB) was purchased from Sigma-Aldrich, recrystallized from heptane and sublimated at $100{ }^{\circ} \mathrm{C}$ prior to use. Anhydrous (99.5\%) $\mathrm{N}$ methyl-2-pyrrolidinone (NMP) was purchased from SigmaAldrich.

\section{Polymers' synthesis}

Polymers were synthesized using a nucleophilic aromatic substitution procedure previously reported. ${ }^{21}$ Typically, $5.0 \mathrm{mmol}$ of TMBP or HMBP, $5.0 \mathrm{mmol}$ of DFB and $10 \mathrm{~mL}$ of NMP were put into a $50 \mathrm{~mL}$ three necked flask, equipped with a mechanical stirrer and a Dean-Stark trap filled with toluene, and blanketed by a flux of dry nitrogen. The flask was immersed into a regulated oil bath, which was heated to $155{ }^{\circ} \mathrm{C}$. After a homogeneous solution was obtained, $7.5 \mathrm{mmol}$ of $\mathrm{K}_{2} \mathrm{CO}_{3}$ and $5 \mathrm{~mL}$ of toluene were added into the flask. The reaction was stirred at $155{ }^{\circ} \mathrm{C}$ for $3 \mathrm{~h}$ to azeotropically remove water and toluene, and then the bath was heated to $175{ }^{\circ} \mathrm{C}$. Toluene and water were drained from the Dean-Stark trap, and the reaction was maintained for $24 \mathrm{~h}$. The obtained viscous solution was diluted with additional NMP $(10 \mathrm{~mL})$ and the polymer was then precipitated onto rapidly stirred distilled water to produce a fibrous solid, which was filtered off and boiled several times in water to remove any residual salt and other by-products. Next, the polymer was washed with a mixture of distilled water and methanol (1/1), methanol and dried in a vacuum oven at $200{ }^{\circ} \mathrm{C}$ overnight. For both polymers quantitative yields were obtained.

TMPB-DFB. ${ }^{1} \mathrm{H}$ NMR (300 $\left.\mathrm{MHz}, \mathrm{CDCl}_{3}\right), \delta(\mathrm{ppm})=2.20$ $\left(12 \mathrm{H}, \mathrm{s}, \mathrm{CH}_{3}\right), 6.88(4 \mathrm{H}, \mathrm{d}, \mathrm{CH}), 7.34(4 \mathrm{H}, \mathrm{s}, \mathrm{CH}), 7.78(4 \mathrm{H}, \mathrm{d}$, $\mathrm{CH}) .{ }^{13} \mathrm{C} \mathrm{NMR}\left(75 \mathrm{MHz}, \mathrm{CDCl}_{3}\right), \delta(\mathrm{ppm})=194.53(1 \mathrm{C}, \mathrm{s}), 162.82$ (2C), 148.50 (1C), 139.44 (2C), 134.41 (4C), 132.54 (5C), 131.62 (2C), 129.85 (2C), 127.62 (2C), 114.53 (4C), 17.06 (2C), 13.45 (2C).

HMPB-DFB. ${ }^{1} \mathrm{H}$ NMR (300 $\left.\mathrm{MHz}, \mathrm{CDCl}_{3}\right), \delta(\mathrm{ppm})=2.01$ $\left(6 \mathrm{H}, \mathrm{s}, \mathrm{CH}_{3}\right), 2.13\left(12 \mathrm{H}, \mathrm{s}, \mathrm{CH}_{3}\right), 6.88(4 \mathrm{H}, \mathrm{d}, \mathrm{CH}), 6.93(2 \mathrm{H}, \mathrm{s}$, $\mathrm{CH}), 7.81(4 \mathrm{H}, \mathrm{d}, \mathrm{CH}) .{ }^{13} \mathrm{C} \mathrm{NMR}\left(75 \mathrm{MHz}, \mathrm{CDCl}_{3}\right) \delta(\mathrm{ppm})=$ 194.48 (1C), 161.60 (2C), 149.54 (1C), 139.40 (1C), 134.42 (4C), 132.63 (5C), 131.47 (1C), 129.88 (1C), 129.82 (2C), 127.84 (3C), 114.51 (4C), 17.05 (2C), 16.40 (2C), 13.27 (2C).

\section{Film casting}

Dense homogeneous membranes were prepared using a solution casting method. $0.500 \mathrm{~g}$ of polymer was dissolved in $10 \mathrm{~mL}$ of chloroform, and the solution was filtered through a $3.1 \mu \mathrm{m}$ fiberglass Symta ${ }^{\circledR}$ syringe filter, poured onto a glass ring placed on a leveled glass plate, and maintained at room temperature overnight to remove most of the solvent. The membranes were peeled off of the glass and placed into a vacuum oven at $100{ }^{\circ} \mathrm{C}$ for $24 \mathrm{~h}, 120^{\circ} \mathrm{C}$ for $2 \mathrm{~h}, 150{ }^{\circ} \mathrm{C}$ for $2 \mathrm{~h}, 180{ }^{\circ} \mathrm{C}$ for $1 \mathrm{~h}$ and $200{ }^{\circ} \mathrm{C}$ for $15 \mathrm{~min}$. Finally, they were slowly cooled in the oven. The absence of residual solvent was confirmed by thermogravimetric analysis. The thickness of the circular membranes (area $70.8 \mathrm{~cm}^{2}$ ) ranged from 45 to $55 \mu \mathrm{m}$. The thickness percent uncertainty of a membrane was between 2 and $3 \%$.

\section{UV irradiation}

Circular membranes of $2.5 \mathrm{~cm}$ diameter were irradiated with polychromatic light in air, for different amounts of time on each side, using a $100 \mathrm{~W}$ high pressure $\mathrm{Hg}$-Xe arc lamp (Hammatsu LC8 Lightningcure ${ }^{\mathrm{TM}}$ ) equipped with a $350 \mathrm{~nm}$ glass cut-off, working at $50 \%$ of nominal power. Samples were placed at $15 \mathrm{~cm}$ from the bulb of the UV lamp and irradiated during times between 30 and $60 \mathrm{~min}$ (per side). In this way, the gradient of crosslinking due to the thickness of the membranes was reduced.

The degree of crosslinking was estimated from the gel fraction by eqn (1).

$$
\text { Gel fraction }(\%)=\frac{W_{\text {final }}}{W_{\text {initial }}} \times 100
$$

where $W_{\text {inital }}$ is the initial weight of sample before crosslinking and $W_{\text {final }}$ is the weight of the crosslinked sample after extracting the soluble fraction. $W_{\text {final }}$ was determined by immersing the crosslinking samples in chloroform at room temperature under gentle stirring for $24 \mathrm{~h}$. Next the samples were dried at $120^{\circ} \mathrm{C}$ under vacuum for $12 \mathrm{~h}$ and weighed again.

\section{Techniques}

${ }^{1} \mathrm{H}$ and ${ }^{13} \mathrm{C}$ NMR spectra were recorded on a Bruker Avance-300 spectrometer operating at 300 and $75 \mathrm{MHz}$ in $\mathrm{CDCl}_{3}$. Fourier Transform Infrared (FTIR) spectra were registered on a Perkin Elmer Spectrum RX I FTIR spectrometer equipped with an ATR 
Accessory. Ultraviolet-visible spectra were acquired using a Perkin Elmer Lambda $35 \mathrm{UV} /$ vis spectrometer. Inherent viscosities were measured at $25{ }^{\circ} \mathrm{C}$ with an Ubbelohde viscometer using NMP as solvent at $0.5 \mathrm{~g} \mathrm{dL}^{-1}$ concentration. The polymers' solubility was determined by mixing $10 \mathrm{mg}$ of polymer with $1 \mathrm{~mL}$ of solvent, followed by stirring for $12 \mathrm{~h}$ at room temperature. The samples that were not soluble were stirred for 5 additional hours at $60{ }^{\circ} \mathrm{C}$. Thermogravimetric analysis (TGA) were performed on a TA-Q500 analyzer under nitrogen flux $\left(60 \mathrm{~mL} \mathrm{~min}^{-1}\right.$ ) at $10{ }^{\circ} \mathrm{C} \mathrm{min}^{-1}$. Differential scanning calorimetry (DSC) was recorded on a TA Q-2000 instrument in nitrogen atmosphere $\left(50 \mathrm{~mL} \mathrm{~min}^{-1}\right)$ at $20{ }^{\circ} \mathrm{C} \mathrm{min}^{-1}$. Wide-angle-X-ray scattering (WAXS) patterns were recorded in the reflection mode at room temperature, using a Bruker D8 Advance diffractometer provided with a Goebel Mirror and a PSD Vantec detector. $\mathrm{CuK}_{\alpha}$ (wavelength $\lambda=1.54 \AA$ ) radiation was used. A step-scanning mode was employed for the detector, with a $2 \theta$ step of $0.024^{\circ}$ and $0.5 \mathrm{~s}$ per step. Density of membranes $(\rho)$ was determined from Archimedes' principle using a top-loading electronic XS105 Dual range Mettler Toledo balance equipped with a density measurement kit. Six density measurements were made for each sample where the samples were sequentially weighed in air and into high purity isooctane at $25{ }^{\circ} \mathrm{C}$. The density was calculated from eqn (2):

$$
\rho=\rho_{\text {liquid }} \times \frac{\omega_{\text {air }}-\omega_{\text {liquid }}}{\omega_{\text {air }}}
$$

where $\rho_{\text {liquid }}$ is the density of isooctane, $\omega_{\text {air }}$ is the weight of the sample in air and $\omega_{\text {liquid }}$ is its weight when submerged in isooctane.

\section{Gas permeability measurements}

The pure gas permeation properties for $\mathrm{He}, \mathrm{O}_{2}, \mathrm{~N}_{2}$ and $\mathrm{CH}_{4}$ were measured at $30{ }^{\circ} \mathrm{C}$ and an upstream pressure of 3 bar using a lab-made constant volume/variable pressure apparatus. The permeation of $\mathrm{CO}_{2}$ was measured in the upstream pressure range from 1 to 25 bar. The membranes were previously measured before being irradiated with UV light. After the membrane was mounted inside the permeation cell, both upstream and downstream chambers were exposed to high vacuum overnight to degas the membrane. The upstream pressure was adjusted to the desired value before starting the permeation experiments $(t=0 \mathrm{~s})$, and then the increase of the permeate pressure was recorded as a function of time. All gases were allowed to permeate until the steady-state (ss) conditions were attained. The permeability coefficient $(P)$ was calculated from eqn (3).

$$
P=\frac{273}{76} \frac{V l}{A T p_{0}}\left[\left(\frac{\mathrm{d} p(t)}{\mathrm{d} t}\right)_{\mathrm{ss}}-\left(\frac{\mathrm{d} p(t)}{\mathrm{d} t}\right)_{\text {leak }}\right]
$$

where $A$ and $l$ are the effective area and the thickness of the membrane, respectively, $V$ is the downstream volume, $T$ is the absolute experimental temperature, $p_{0}$ is the upstream pressure, $(\mathrm{d} p(t) / \mathrm{d} t)_{\mathrm{ss}}$ is the steady state rate of the pressure-rise, and $(\mathrm{d} p(t) / \mathrm{d} t)_{\text {leak }}$ is the system leak rate, which was less than $1 \%$ of $(\mathrm{d} p(t) / \mathrm{d} t)_{\mathrm{ss}}$.
The diffusion coefficient $(D)$ was obtained from the relation given in eqn (4).

$$
D=\frac{l^{2}}{6 \theta}
$$

where $\theta$, the time lag, corresponds to the intercept of the time axis with the straight line in the steady state.

The solubility coefficient $(S)$ was indirectly evaluated from $S$ $=P / D$ assuming the validity of the solution-diffusion permeation model. The ideal selectivity for a pair of gases A and B, which was calculated as the ratio for individual single gas permeability, can be decoupled into diffusivity selectivity and solubility selectivity (eqn (5)).

$$
\alpha_{\mathrm{B}}=\frac{P(\mathrm{~A})}{P(\mathrm{~B})}=\frac{D(\mathrm{~A})}{D(\mathrm{~B})} \times \frac{S(\mathrm{~A})}{S(\mathrm{~B})}
$$

\section{Computational methods}

Computational chemistry was carried out by initially optimizing the structures at the AM1 level of theory. ${ }^{22}$ Subsequently, electronic energies and structures were calculated by full optimization, without any geometrical constraint, by using the Becke's three-parameter hybrid functional ${ }^{23}$ and the Lee et al. correlation functional with the $6-31 \mathrm{G}(\mathrm{d}, \mathrm{p})$ basis set. ${ }^{24}$ The Restricted Hartree-Fock method, where the molecule is a closed shell system with all orbitals doubly occupied, was used for ground state molecules (RHF/B3LYP/6-31G(d,p)), while the unrestricted Hartree-Fock method, where the molecule is an open shell system with some of the electrons not paired, was used for radical species (UHF/B3LYP/6-31G(d,p)). ${ }^{25}$ Frequency calculations were used for all minimized structures to ensure that satisfactory minima were obtained. HOMO energies, zero-point electronic energies were determined by doing a single-point calculation with the hybrid B3LYP/6-31G+(d,p). ${ }^{26}$ The Gaussian 09 v.A1 and Gaussview v.5.08 program packages were used throughout this work. ${ }^{27,28}$ Molecular graphs and pictures were achieved with the GaussView and Arguslab programs. ${ }^{28,29}$

\section{Results and discussion}

\section{Synthesis and characterization of polymers}

Two aromatic PEEKs were synthesized via nucleophilic aromatic substitution. ${ }^{30}$ The reaction proceeded by formation of bisphenolates, and subsequent ipso ether addition on the fluorine-substituted carbon atoms of the DFB, yielding a Meisenheimer complex, and posterior elimination of fluorine ions to give aromatic ether linkages. The synthetic scheme and the chemical structure of both polymers are shown in Fig. 1.

Chemical structures of polymers were confirmed by ${ }^{1} \mathrm{H}$ and ${ }^{13} \mathrm{C}$ NMR. As an example, Fig. 2 and 3 show the ${ }^{1} \mathrm{H}$ NMR spectra of both polymers with the assignment of the signals. The integrations of the signals correspond well to the total number of protons.

Despite the bulkiness introduced by the methyl groups on the diamines moieties, the solubility of polymers was poor in most common organic solvents, as seen in Table 1 . None were 
<smiles>[R6]c1c(-c2cc(C)c(O)c(C)c2[R6])cc(C)c(O)c1C</smiles>

TMBP or HMBP

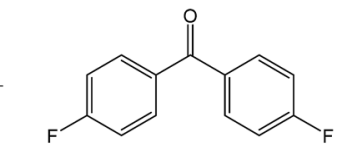

DFB

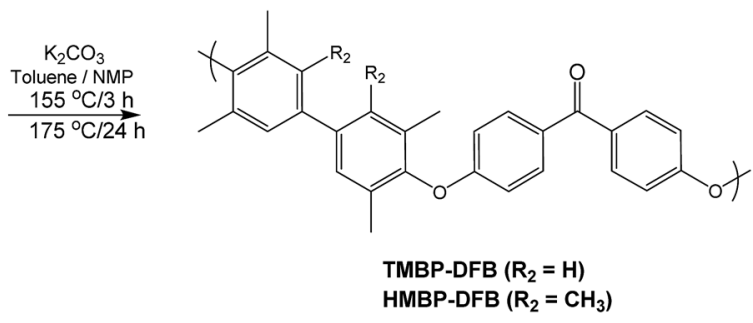

Fig. 1 Synthesis of the poly(ether ether ketone)s.

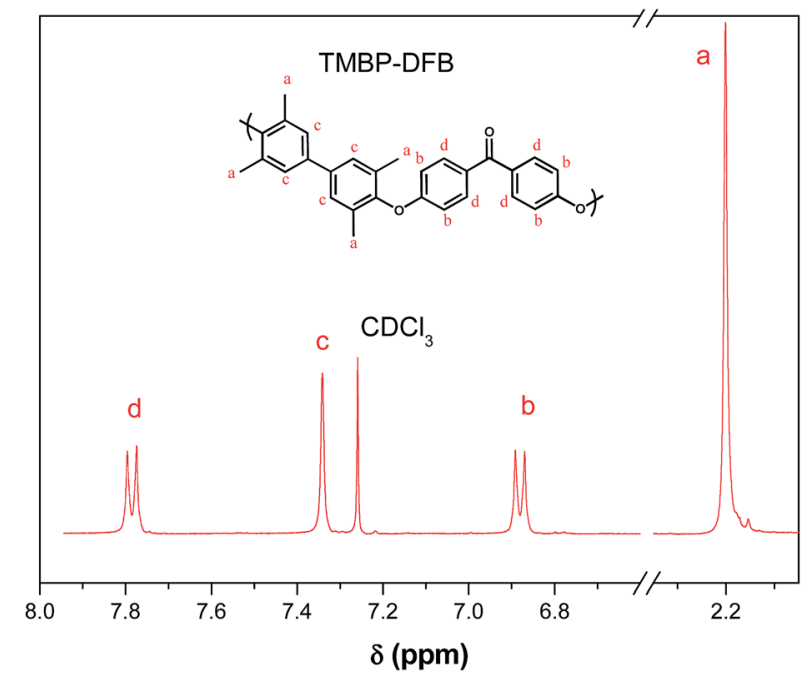

Fig. $2{ }^{1} \mathrm{H}-\mathrm{NMR}$ spectrum of TMBP-DFB in $\mathrm{CDCl}_{3}$.

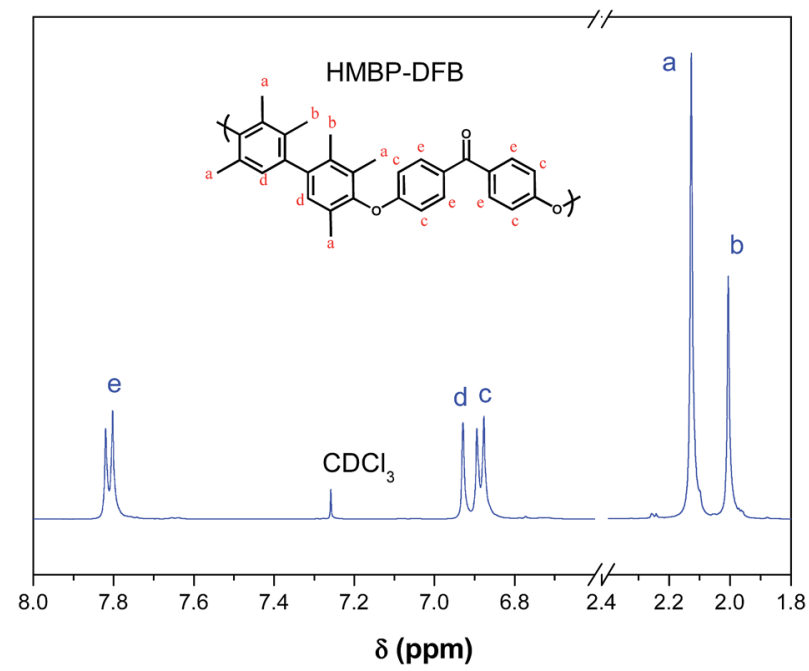

Fig. $3{ }^{1} \mathrm{H}-\mathrm{NMR}$ spectrum of $\mathrm{HMBP}-\mathrm{DFB}$ in $\mathrm{CDCl}_{3}$.
Table 1 Inherent viscosity $\left(\eta_{\text {inh }}\right)$ and solubility of PEEKs

\begin{tabular}{|c|c|c|c|c|c|c|c|}
\hline \multirow[b]{2}{*}{ Name } & \multirow[b]{2}{*}{$\eta_{\mathrm{inh}^{a}}{ }^{a}$} & \multicolumn{6}{|c|}{ Solubility $^{b}$} \\
\hline & & NMP & DMAc & DMF & DMSO & THF & $\mathrm{CHCl}_{3}$ \\
\hline TMBP-DFB & 1.34 & + & - & - & - & - & + \\
\hline HMBP-DFB & 0.64 & + & - & - & - & - & + \\
\hline
\end{tabular}

soluble in typical GPC solvents, such as DMF or THF, and molecular weights of polymers were then estimated by measuring the inherent viscosities, whose values are also listed in Table 1. The values for both polymers were high enough, in particular for TMBP-DFB, indicating that high molecular weight polymers have been attained. The two polymers were soluble in $\mathrm{CHCl}_{3}$ and NMP, which allowed for the preparation of films by casting. The mechanical properties of the films were good, with elastic moduli near to $1.5 \mathrm{GPa}$ and tensile strength values in the range of 90-110 MPa, to be used as gas separation membranes.

Additional thermal and physical properties of PEEKs are given in Table 2. Both polymers had thermal stabilities above $450{ }^{\circ} \mathrm{C}$ in nitrogen atmosphere, with high char yields, about $50 \%$, as corresponds to highly aromatic structures. As expected, the glass transition temperatures, $T_{\mathrm{g}} \mathrm{s}$, were also high. No significant effect of the diamine structure on $T_{\mathrm{g}}$ was apparent, probably due to the conformational flexibility provided by the ether groups.

Fractional free volume, FFV, was calculated from the experimental density of the membrane $(\rho)$ using the relation (eqn $(6)):^{31}$

$$
\mathrm{FFV}=\left(V-1.3 V_{\mathrm{w}}\right) / V
$$

Where $V(=1 / \rho)$ is the polymer specific volume and $V_{\mathrm{w}}$ is the van der Waals volume, which was estimated using the HyperChem computer program. ${ }^{32}$ The obtained values were similar, indicating that the presence of the two methyl groups on $2,2^{\prime}$ positions in the diamine HMBP did no increase the FFV. The values were considerably high compared to that of Matrimid ${ }^{\circledR}$ $(\mathrm{FFV}=0.110)$, which is a commercial polyimide widely used in gas separation. ${ }^{33}$

The X-ray diffraction patterns revealed the amorphous nature of PEEKs, as seen in Fig. 4. The most probable intersegmental distance between the chains $(d)$ was determined from the amorphous halo maximum using the Bragg equation (eqn (7)):

$$
\lambda=2 d \sin \Theta
$$

where $d$ is the $d$-spacing and $\Theta$ the scattering angle that corresponds to the amorphous halo maximum. The maxima at $15.8^{\circ}$ and $15.1^{\circ}$ correspond to distances of 0.56 and $0.59 \mathrm{~nm}$ for TMBP-DFB and HMBP-DFB, respectively. Therefore, the two methyl groups on the $2,2^{\prime}$ positions of diamine HMBP only produced small changes in the packing of the polymers chains, which is in agreement with the values of FFV. 
Table 2 Thermal properties, density and fractional free volume of non-irradiated and irradiated PEEK membranes

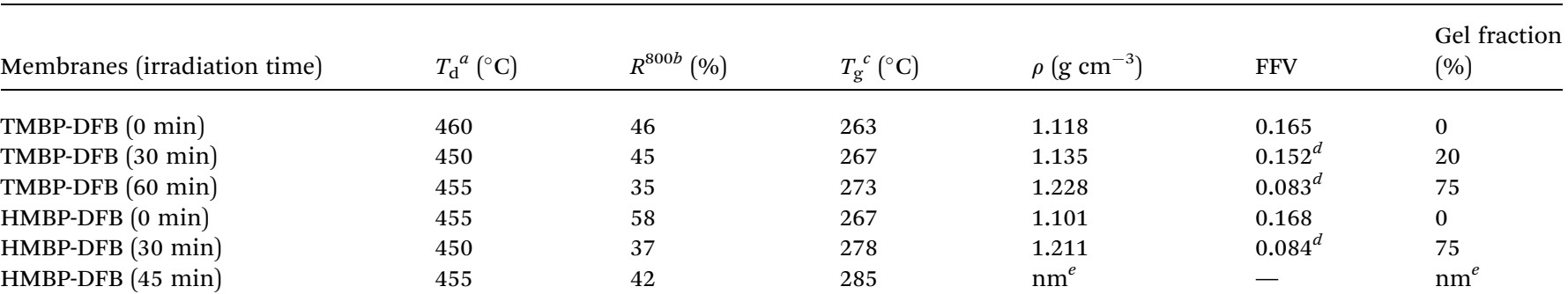

${ }^{a}$ Onset temperature at which decomposition begins. ${ }^{b}$ Char yield at 800C. ${ }^{c} T_{\mathrm{g}}$ value was taken at the half-height of the heat capacity step from the second heating scan. ${ }^{d}$ Estimated by considering that the repeat unit structure and molecular weight remain practically unchanged. ${ }^{e}$ Density and gel fraction could not be measured because the membrane lost its integrity during immersion.

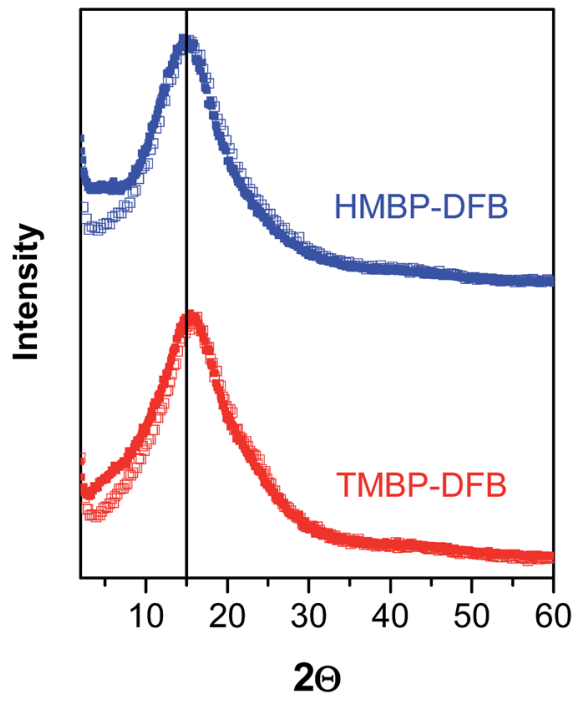

Fig. 4 X-ray diffraction patterns of non-irradiated membranes (solid symbols) and irradiated membranes (open symbols) of PEEKs with gel fraction of $75 \%$.

\section{UV crosslinking of the membranes}

Membranes were irradiated in air, with ultraviolet light of wavelengths higher than $350 \mathrm{~nm}$ to selectively excite the $\mathrm{n}-\pi^{*}$ absorption band of the benzophenone chromophore and then promote its photoreduction through abstraction of a vicinal $\mathrm{H}$ atom. Under these conditions, the undesirable secondary reactions, such as chain scission and/or photooxidation, should be minimized, even during long irradiation times, due to the lower energy of the light above $350 \mathrm{~nm} .^{34}$ The UV-vis spectra of both polymers showed an intense $n-\pi^{*}$ absorption band with no maxima at wavelengths between $350-500 \mathrm{~nm}$, as seen in Fig. 5. The high absorbance values are due to the high concentration of benzophenone units in the membranes. According to the Beer-Lambert law, the fraction of incident light at a particular wavelength diminishes with depth in the film due to absorption. Thus, thick films are expected to have a crosslinking gradient. However, given the extremely high rate constant of benzophenone photoreduction (106-109 $\mathrm{L} \mathrm{mol}^{-1} \mathrm{~s}^{-1}$ ) and the high photoreduction quantum yields (0.45-1) in good hydrogen donating media, ${ }^{35}$ the chromophore should rapidly

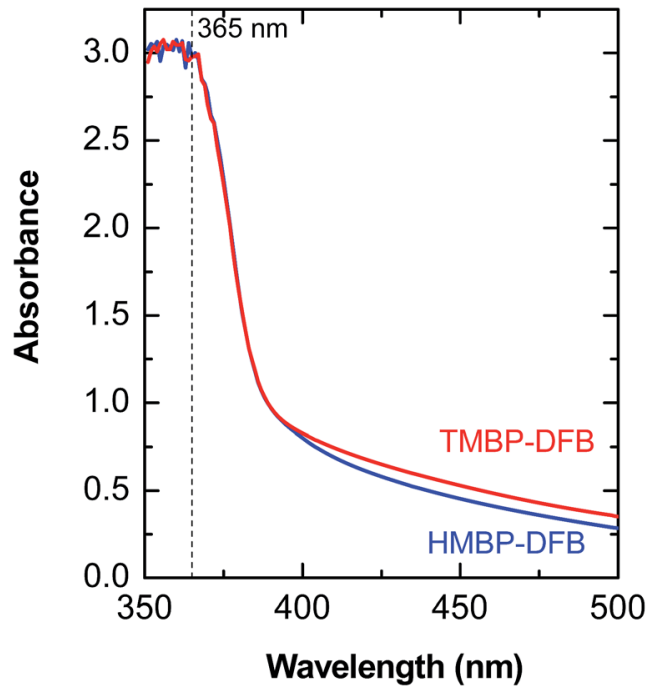

Fig. 5 UV-vis spectra of the ketone containing films. The dashed line corresponds to the emission line for mercury $(\mathrm{Hg})$ at $365 \mathrm{~nm}$.

react as irradiation proceeds, even for low values of incident light in the bottom of the film. In addition, membranes were irradiated in both sides to improve the homogeneity of the crosslinking reaction across the film. Exposure times were set long enough to assure maximum reduction of the benzophenone and minimal damage of mechanical properties of the membranes (irradiation times varying between 30-60 $\mathrm{min}$ ).

Fig. 6 shows the most likely photoreduction mechanism and radical coupling reactions for the crosslinking of polymer chains: (A) the coupling between two benzylic radicals and (B) the coupling of benzylic radical with the ketyl carbon-centered radical. At the same time, benzylic radicals can also react with the oxygen in their surroundings to form peroxides, which tend rapidly to dissociate and yield carboxylic acids among other photooxidation products. $^{\mathbf{3 6}}$

The progress of crosslinking can be monitored by ATR-FTIR spectroscopy, by observing the decrease in the benzophenone carbonyl absorption band at $1652 \mathrm{~cm}^{-1}$ with the UV exposure time. ${ }^{20}$ Fig. 7 displays normalized ATR-FTIR spectra of TMBPDFB and HMBP-DFB films as a function of irradiation time. After baseline correction, the spectra were normalized with respect to the band at $1592 \mathrm{~cm}^{-1}$, attributed to the stretching of 


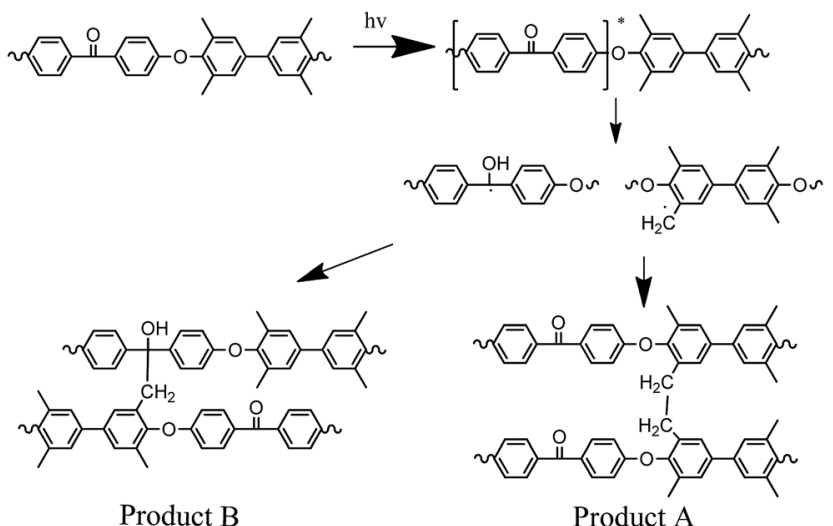

Fig. 6 Expected mechanism of UV-induced crosslinking.

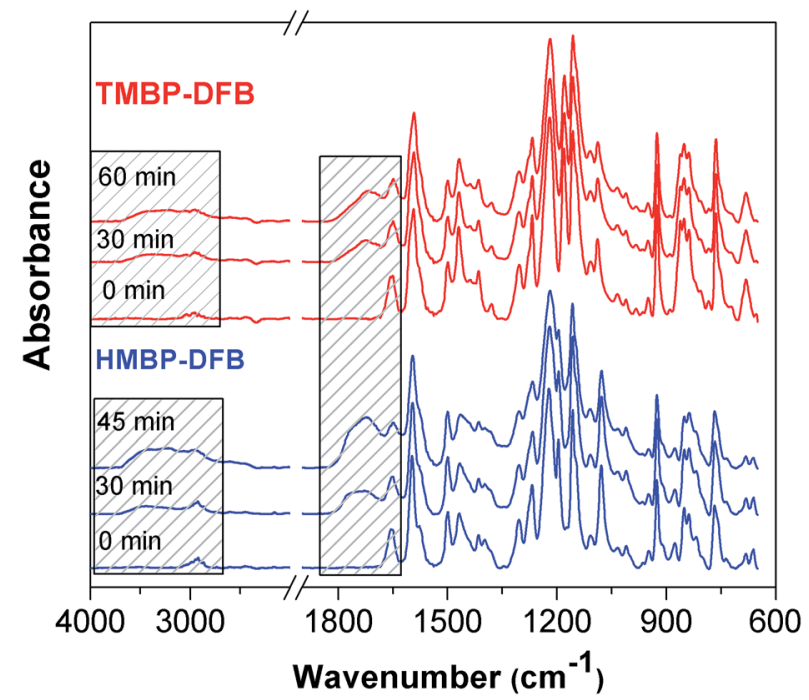

Fig. 7 FTIR spectra of PEEKs films as a function of UV-irradiation time. The bands affected by the irradiation are shaded.

substituted benzene moieties, which should remain unaffected by crosslinking. As shown in Fig. 7, the $\mathrm{C}=\mathrm{O}$ stretching band intensity of benzophenone moiety, at $1655 \mathrm{~cm}^{-1}$, decreases with increasing UV irradiation time. Concomitantly, a broad band at around $1730 \mathrm{~cm}^{-1}$, which is attributed to carbonyl stretching from aldehydes and carboxylic acids generated from photooxidation, emerges and increases progressively in intensity with increasing UV irradiation time. ${ }^{37}$ These changes are also accompanied by the appearance of a new band at around $3300 \mathrm{~cm}^{-1}$ related to the stretching of hydroxyl groups generated via crosslinking and/or photooxidation. It should be noted that the benzophenone band of both membranes do not completely disappear even after $60 \mathrm{~min}$ irradiation, indicating that its photoreduction is not complete. Unfortunately, the quantitative analysis of the area under the peak at $1655 \mathrm{~cm}^{-1}$ could not be performed due to its overlapping with the broad peak at $1730 \mathrm{~cm}^{-1}$, which increases in intensity as the irradiation time increases. In addition, the peak at $1730 \mathrm{~cm}^{-1}$ was stronger for HMBP-DFB than for TMBP-DFB after $45 \mathrm{~min}$ of irradiation. This fact suggested a more rapid formation of photooxidation products in the case of HMBP-DFB, which was directly related to the loss of mechanical properties of the membranes upon longer irradiation time. Therefore, $60 \mathrm{~min}$ was set as the maximum irradiation time for TMBP-DFB and a maximum of 30 min of irradiation was used for HMBP-DFB.

The gel fraction of the irradiated membranes can be considered as a measure for assessing the extent of crosslinking. As expected, the gel fractions increased with increasing irradiation time (see Table 2). Thus, the gel fractions for TMBPDFB samples went from $20 \%$ at $t_{\text {irr }}=30$ min to $75 \%$ at $t_{\text {irr }}=$ $60 \mathrm{~min}$, confirming that the crosslinked thickness progressed with irradiation time. For HMBP-DFB membranes the exposure time required to achieve $75 \%$ gel fraction was considerably shorter, only $30 \mathrm{~min}$. When HMBP-DFB membrane was irradiated for $45 \mathrm{~min}$ it became brittle, and the gel fraction could not be measured because it lost its integrity during immersion. Thereby, it was not tested as a gas separation membrane. This behavior could be consistent with the higher proportion of benzylic methyl groups in HMBP units, but could be also indicative of a higher reactivity of these groups to give radicals in comparison to those of TMBP-DFB. Therefore, we have performed quantum mechanical calculations to determine the ability of the different methyl groups to give $-\mathrm{CH}_{2}{ }^{\cdot}$ radicals. These calculations will be commented on below.

The density of both irradiated membranes with $75 \%$ gel fraction increased by $10 \%$ compared to the value of nonirradiated ones, as seen in Table 2. This increase indicates a densification of the polymer membranes upon photocrosslinking, which could be associated with a decrease in FFV. In fact, considering that the chemical structure of polymers hardly changes during crosslinking, the FFV of crosslinked films significantly decreased with the irradiation time (Table 2). The FFV decreased to half the original value for the indicated $10 \%$ increase in density. Moreover, the FFV was the same for the crosslinked membranes of both PEEKs with a $75 \%$ gel fraction. This densification of the membrane would be expected to be reflected in a decrease of the more probably intersegmental distances obtained by X-ray diffraction. However, no significant change in the position of the amorphous halo was visible, as seen in Fig. 4, where the patterns of non-irradiated membranes are compared to those of crosslinked ones with a $75 \%$ gel fraction. Only, a narrowing on the lower angle side of the amorphous halo of the crosslinked membrane patterns could be observed.

As it can be also seen in Table 2, the thermal stability of the membranes was not affected by crosslinking. In contrast, the glass transition temperatures of the irradiated membranes increased as the extent of crosslinking increased. The $T_{\mathrm{g}} \mathrm{s}$ of crosslinked membranes with a $75 \%$ of gel fraction were about $10{ }^{\circ} \mathrm{C}$ higher than the values of non-crosslinked ones.

\section{Quantum mechanical calculations on radical formation ability}

As commented on above, the crosslinking of the membranes takes place through the reaction between radicals previously formed by UV irradiation. As the combination of two radicals 
occurs without a significant energy barrier, the process that controls the feasibility of crosslinking is the formation of the radicals. To assess the ability of the different groups to yield radicals, and therefore, to determine the influence of the number of methyls on the crosslinking process, a quantum mechanical study of the heat of formation of several models that represent the structure of the polymers and of their corresponding radicals, obtained by abstraction of one hydrogen radical, was performed. As the aromatic ketones are common in all structures, the models represent the moiety that is different in every case. With comparative purposes, the radical derived from tetramethyl bisphenol A (M-TMBPA), and two possible radicals formed from tetramethyl bisphenol F (M-TMBPF) were also studied, because these monomers have been previously employed in the same type of reaction. ${ }^{20,21}$ All the models are shown in Fig. 8. In the case of M-TMBP, only one monoradical is possible, corresponding to its formation on methyl groups placed in 3-position. However, in MHMPB, three different radicals are possible, depending on the methyl groups which suffer the reaction.

The second column of Table 3 shows the heat of formation, in $\mathrm{eV}$, of the model compounds and their corresponding radicals. Column 3 shows the energy differences, in $\mathrm{eV}$ and in $\mathrm{kcal} \mathrm{mol}^{-1}$, between the radicals and the model compounds (it should be taken into account that the loss of a hydrogen

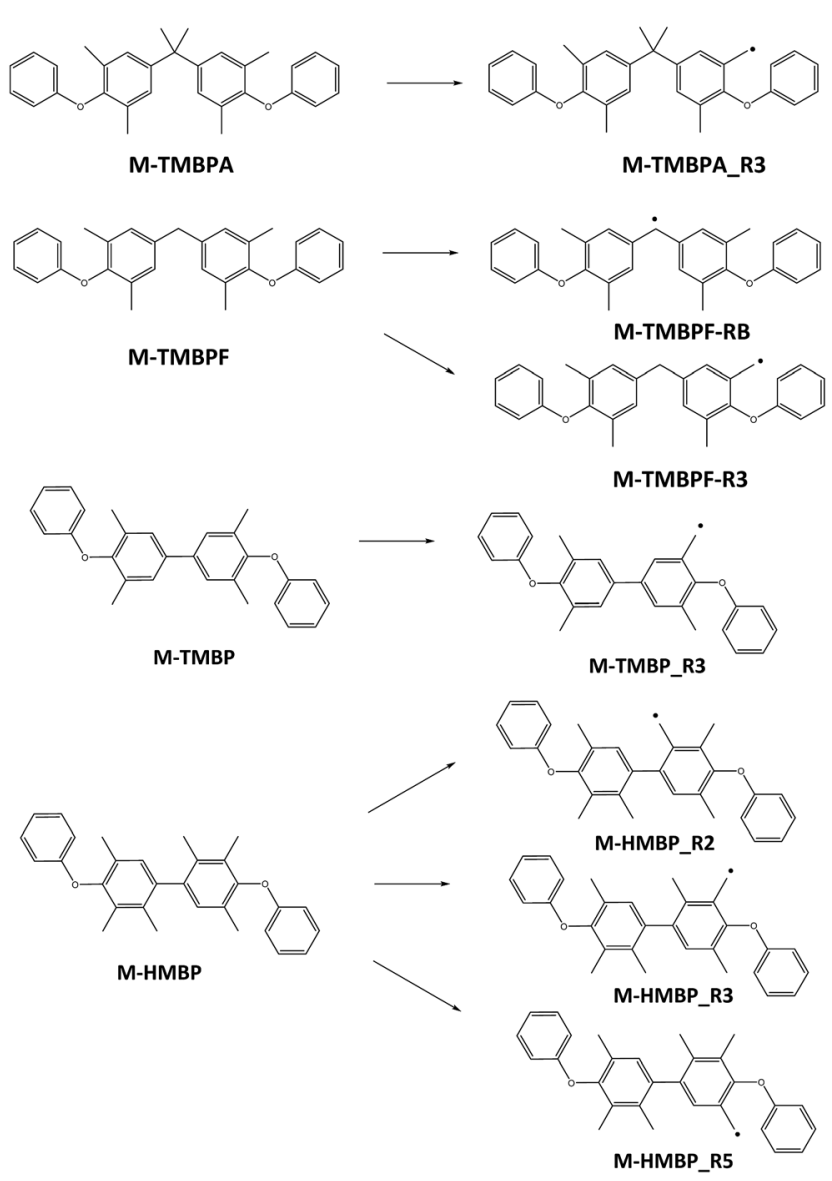

Fig. 8 Structure of the possible radicals that can be obtained from the model structures.
Table 3 Energy (heat of formation) of the models and radicals, as calculated by quantum mechanical methods

\begin{tabular}{llll}
\hline & & \multicolumn{2}{l}{$\begin{array}{l}\text { Energy difference (EM_R + } \\
\text { EH) - EM }\end{array}$} \\
\cline { 3 - 4 } Molecule & Energy (eV) & $(\mathrm{eV})$ & $\left(\mathrm{kcal} \mathrm{mol}^{-1}\right)$ \\
\hline M-TMBPA & -36765.95 & - & - \\
M-TMBPA-R3 & -36748.22 & 4.117 & 94.939 \\
M-TMBPF & -34626.41 & - & - \\
M-TMBPF-RB & -34609.06 & 3.737 & 86.176 \\
M-TMBPF-R3 & -34608.67 & 4.127 & 95.169 \\
M-TMBP & -33556.63 & - & - \\
M-TMBP-R3 & -33538.88 & 4.137 & 95.400 \\
M-HMBP & -35695.25 & - & - \\
M-HMBP-R2 & -35678.57 & 3.067 & 70.725 \\
M-HMBP-R3 & -35678.54 & 3.097 & 71.417 \\
M-HMBP-R5 & -35678.53 & 3.107 & 71.648 \\
& & &
\end{tabular}

radical has also to be considered; energy of hydrogen radical $=$ $-13613 \mathrm{eV}$ ). From these data, it can be seen that the maximum energy difference corresponds to M-TMBP-R3 that, consequently, is more difficult to form during irradiation, but the energy is very similar to that of M-TMBPA-R3 and M-TMBPF-R3. This indicates that, for tetramethyl-substituted bisphenols, the reactivity is similar in all cases, irrespective of the bridge between the rings. Moreover, in the case of M-TMBPF, the energy difference is lower for the bridge radical, which consequently is more probable than any of the methylene radicals.

As to the hexamethyl-substituted model (M-HMBP), the presence of additional methyl groups seems to favor the formation of radicals, irrespective of the methyl group affected. In fact, the energy of the three possible radicals is approximately $24 \mathrm{kcal} \mathrm{mol}{ }^{-1}$ lower than the energy of the methylene radicals formed in the other models, and about $15 \mathrm{kcal} \mathrm{mol}^{-1}$ lower than for the bridge radical in the case of M-TMBPF.

Consequently, the theoretical results support the experimental ones, commented on above, where the polymer HMBPDFB reached the same gel fraction as TMBP-DFB did in a shorter irradiation time, and the higher reactivity of the polymer cannot be solely attributed to the higher amount of methyl groups, but to the higher feasibility of formation of these radicals. Moreover, these results indicate that the HMBP-DBF should be the most reactive among any of the polymers considered here.

\section{Gas transport properties}

The single gas permeabilities of $\mathrm{He}, \mathrm{O}_{2}, \mathrm{~N}_{2}, \mathrm{CH}_{4}$ and $\mathrm{CO}_{2}$ for both linear PEEKs and UV-crosslinked analogs were determined using a constant volume-variable pressure permeator, and the results at a feed pressure of 3 bar and $30{ }^{\circ} \mathrm{C}$ are shown in Table 4. Gas permeabilities of linear PEEK membranes were lower for HMBP-DFB, except for He. This decrease in permeability was also accompanied by an improvement in selectivity. Taking into account that FFV is slightly higher in the latter polymer and, moreover, $\mathrm{He}$ is the gas molecule with smaller size, the lower permeabilities would be consistent with a distribution of FFV containing a higher number of smaller 
elements, which would be not accessible to the rest of gases with larger sizes. In contrast, $P\left(\mathrm{CO}_{2}\right)$ is close to $P(\mathrm{He})$ and $P\left(\mathrm{CH}_{4}\right)$ is somewhat higher than $P\left(\mathrm{~N}_{2}\right)$ in the case of TMBP-DFB membrane, which is a typical behavior of polymers having high FFV. ${ }^{38-40}$ These results suggest that the methyl groups could be partially occupying the void space (internal free volume), which would cause a decrease in both the overall FFV and the size of accessible holes. ${ }^{41}$

The UV-crosslinking process led to a drop in gas permeabilities in both polymers. The decrease was higher for gases with large kinetic diameter, and was much higher for $\mathrm{CH}_{4}$ gas. This is the typical behavior of glassy polymers with relatively low FFV. For the membranes with a $75 \%$ gel fraction, $P\left(\mathrm{CO}_{2}\right)$ was almost five times lower than $P(\mathrm{He})$ and $P\left(\mathrm{CH}_{4}\right)$ was two times lower than $P\left(\mathrm{~N}_{2}\right)$. This decrease in permeability coefficients brought about a significant improvement of the $\mathrm{O}_{2} / \mathrm{N}_{2}$ and $\mathrm{CO}_{2} /$ $\mathrm{CH}_{4}$ selectivities. These facts can be related to the above commented on decrease in FFV with crosslinking.

Since permeability is the product of diffusion, $D$, and solubility, $S$, coefficients, the selectivity can be separated in diffusivity selectivity and solubility selectivity and the values for linear and crosslinked membranes are listed in Tables 5 and 6.

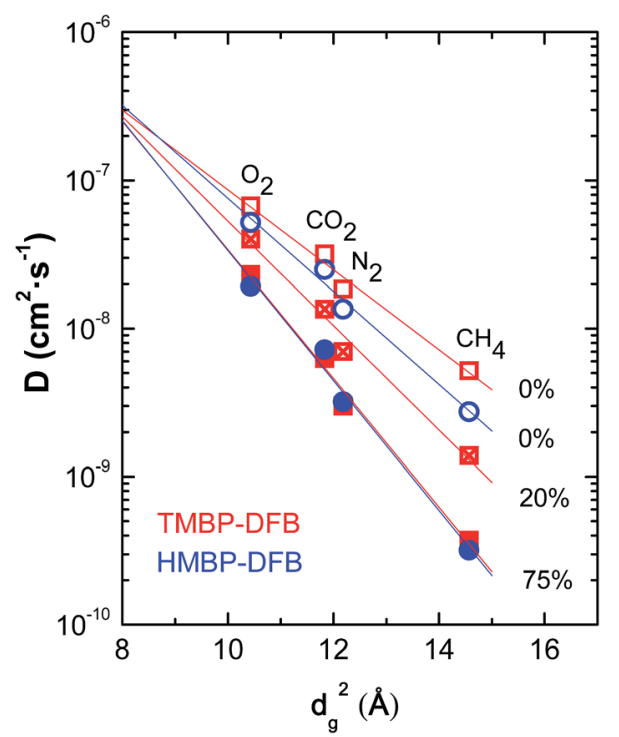

Fig. 9 Dependence of diffusion coefficient on gas diameter squared for non-irradiated (open symbols) and irradiated (solid symbols) membranes. The numbers indicate the gel fraction of the membranes. The lines correspond to the linear fits to eqn (8).

Table 4 Permeabilities and ideal selectivities at 3 bar and $30{ }^{\circ} \mathrm{C}$

\begin{tabular}{llllllll}
\hline & \multicolumn{2}{c}{ Permeability ${ }^{a}$ (barrer) } & & & \multicolumn{2}{c}{ Ideal selectivity } \\
\cline { 2 - 6 } Sample (time of irradiation) & $P(\mathrm{He})$ & $P\left(\mathrm{O}_{2}\right)$ & $P\left(\mathrm{~N}_{2}\right)$ & $P\left(\mathrm{CO}_{2}\right)$ & $P\left(\mathrm{CH}_{4}\right)$ & $P\left(\mathrm{O}_{2}\right) / P\left(\mathrm{~N}_{2}\right)$ & $P\left(\mathrm{CO}_{2}\right) / P\left(\mathrm{CH}_{4}\right)$ \\
\hline TMBP-DFB & $45 \pm 1$ & $8.3 \pm 0.1$ & $1.74 \pm 0.04$ & $41 \pm 1$ & $2.11 \pm 0.06$ & $4.8 \pm 0.1$ & $19.3 \pm 0.7$ \\
TMBP-DFB (30 min) & $38 \pm 1$ & $4.7 \pm 0.1$ & $0.72 \pm 0.02$ & $18.8 \pm 0.6$ & $0.57 \pm 0.02$ & $6.5 \pm 0.2$ & $33 \pm 2$ \\
TMBP-DFB (60 min) & $37 \pm 1$ & $2.73 \pm 0.06$ & $0.30 \pm 0.01$ & $8.3 \pm 0.3$ & $0.155 \pm 0.006$ & $9.1 \pm 0.4$ & $53 \pm 3$ \\
HMBP-DFB & $51 \pm 1$ & $6.38 \pm 0.06$ & $1.15 \pm 0.02$ & $28.4 \pm 0.4$ & $1.06 \pm 0.02$ & $5.5 \pm 0.1$ & $26.8 \pm 0.6$ \\
HMBP-DFB (30 min) & $41 \pm 1$ & $2.34 \pm 0.03$ & $0.274 \pm 0.004$ & $8.4 \pm 0.2$ & $0.125 \pm 0.003$ & $8.5 \pm 0.2$ & $67 \pm 3$
\end{tabular}

${ }^{a} 1$ barrer $=10^{-10} \mathrm{~cm}^{3}(\mathrm{STP}) \mathrm{cm}$ per $\mathrm{cm}^{2}$ per s per $\mathrm{cm} \mathrm{Hg}$.

Table 5 Diffusion coefficients and diffusivity selectivities

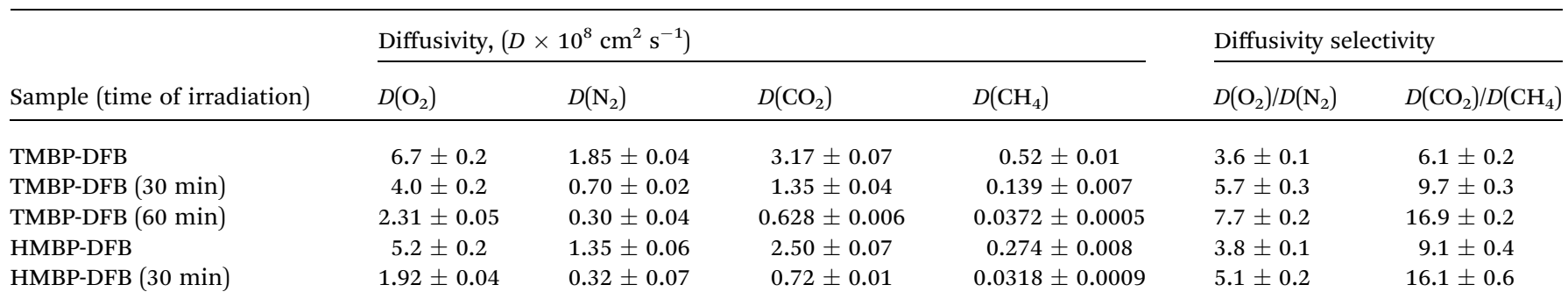

Table 6 Solubility coefficients and solubility selectivities

\begin{tabular}{llccccc}
\hline & \multicolumn{2}{l}{ Solubility, $\left(S \times 10^{3} \mathrm{~cm}^{3}(\mathrm{STP})^{\left.\mathrm{cm}^{-3} \mathrm{cmHg}^{-1}\right)}\right.$} & & \multicolumn{2}{c}{ Solubility selectivity } \\
\cline { 2 - 4 } Sample (time of irradiation) & $S\left(\mathrm{O}_{2}\right)$ & $S\left(\mathrm{~N}_{2}\right)$ & $S\left(\mathrm{CO}_{2}\right)$ & $S\left(\mathrm{CH}_{4}\right)$ & $S\left(\mathrm{O}_{2}\right) / S\left(\mathrm{~N}_{2}\right)$ & $S\left(\mathrm{CO}_{2}\right) / S\left(\mathrm{CH}_{4}\right)$ \\
\hline TMBP-DFB & $12.2 \pm 0.4$ & $9.4 \pm 0.3$ & $129 \pm 4$ & $40 \pm 2$ & $1.30 \pm 0.06$ \\
TMBP-DFB (30 min) & $11.8 \pm 0.6$ & $10.3 \pm 0.4$ & $139 \pm 7$ & $41 \pm 1$ & $1.14 \pm 0.08$ & $3.2 \pm 0.2$ \\
TMBP-DFB (60 min) & $11.8 \pm 0.4$ & $10 \pm 2$ & $132 \pm 7$ & $42 \pm 2$ & $1.2 \pm 0.2$ & $3.1 \pm 0.4$ \\
HMBP-DBF & $12.3 \pm 0.3$ & $8.5 \pm 0.4$ & $114 \pm 3$ & $39 \pm 1$ & $1.45 \pm 0.07$ & $2.9 \pm 0.1$ \\
HMBP-DBF (30 min) & $12.2 \pm 0.6$ & $8.6 \pm 0.4$ & $117 \pm 4$ & $38 \pm 1$ & $1.4 \pm 0.4$ & $3.1 \pm 0.3$
\end{tabular}


As it happens with the permeabilities, the diffusivities for all gases are considerably reduced with increasing irradiation times, and almost the same values are obtained for TMBP-DFB (60 $\mathrm{min}$ ) and for HMBP-DFB (30 $\mathrm{min})$, which have the same value of FFV. However, no effect of crosslinking was observed in solubility and solubility selectivity.

Gas diffusion coefficients for non-crosslinked and crosslinked membranes of TMBP-DFB and HMBP-DFB were compared by correlating data sets using eqn (8). ${ }^{42}$

$$
\ln D=\alpha+\beta d_{\mathrm{g}}^{2}
$$

where $\alpha$ and $\beta$ are fit for each membrane data set, as seen in Fig. 9. $\beta$ parameter serves as a measure of the size sieving ability

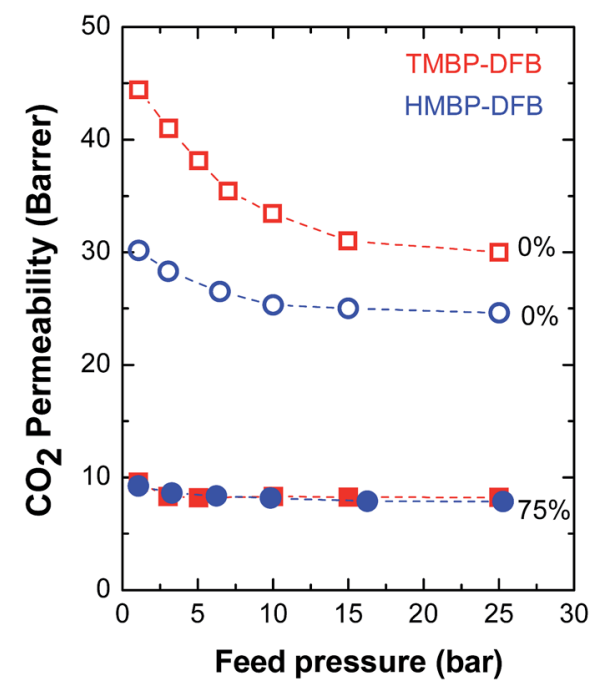

Fig. $10 \mathrm{CO}_{2}$ permeability as a function of feed pressure for nonirradiated (open symbols) and irradiated (solid symbols) membranes. The numbers indicate the gel fraction of the membranes. of the membrane. The gas diameters $\left(d_{\mathrm{g}}\right)$ are taken from ref. 43 . The crosslinked membranes with a $75 \%$ fraction gel showed the greater slope. This result can be directly ascribed to the molecular sieving characteristics of crosslinked membranes facilitating enhanced diffusivity selectivity for molecules with smaller kinetic diameters $\left(\mathrm{O}_{2}=3.23 \AA\right.$ and $\left.\mathrm{CO}_{2}=3.44 \AA\right)$ over those of larger diameters $\left(\mathrm{N}_{2}=3.49 \AA\right.$ and $\left.\mathrm{CH}_{4}=3.817 \AA\right)$. This behavior agrees with the narrowing of the amorphous halo previously observed in the WAXS patterns of the crosslinked membranes (Fig. 4), which is to be related to the disappearance of the large intersegmental distances in the packing of the chains. Therefore, the crosslinking not only would produce a decrease of the FFV but also a more homogeneous size distribution of the free volume elements.

Fig. 10 presents the permeability to $\mathrm{CO}_{2}$ as a function of feed pressure for non-crosslinked membranes and crosslinked ones with a $75 \%$ gel fraction. The permeability of both linear polymers decreases with increasing pressure, mainly at low feed pressures, in a lower extension for HMBP-DFB, consistent with dual-sorption model. ${ }^{18}$ No plasticization behavior was observed in the measured pressure range. Both crosslinked membranes showed the same behavior and, moreover, the effect of the feed pressure on $P\left(\mathrm{CO}_{2}\right)$ was significantly less pronounced.

To evaluate the effect of crosslinking on the productivity of these membranes, Robeson upper bound plots for the $\mathrm{O}_{2} / \mathrm{N}_{2}$ and $\mathrm{CO}_{2} / \mathrm{CH}_{4}$ gas pairs are shown in Fig. 11.,5 The bibliographic data of two different benzophenone-containing PEEKs, one derived from 4,4-methylene bis-(2,6-xylenol) (tetramethyl bisphenol-F or TMBPF) ${ }^{21}$ and other from 2,2-bis(3,5-dimethyl-4hydroxyphenyl)propane (tetramethyl bisphenol-A or TMBPA), ${ }^{15}$ and of Matrimid have been also reported for comparison. Both PEEKs have a similar structure to these described in this paper, but bear a flexibilizing moiety in the bisphenol unit. Crosslinking of the films clearly moves the balance of selectivity versus permeability closer to the Robeson upper bound for both $\mathrm{O}_{2} / \mathrm{N}_{2}$ and $\mathrm{CO}_{2} / \mathrm{CH}_{4}$ gas pairs. The greatest improvement occurs
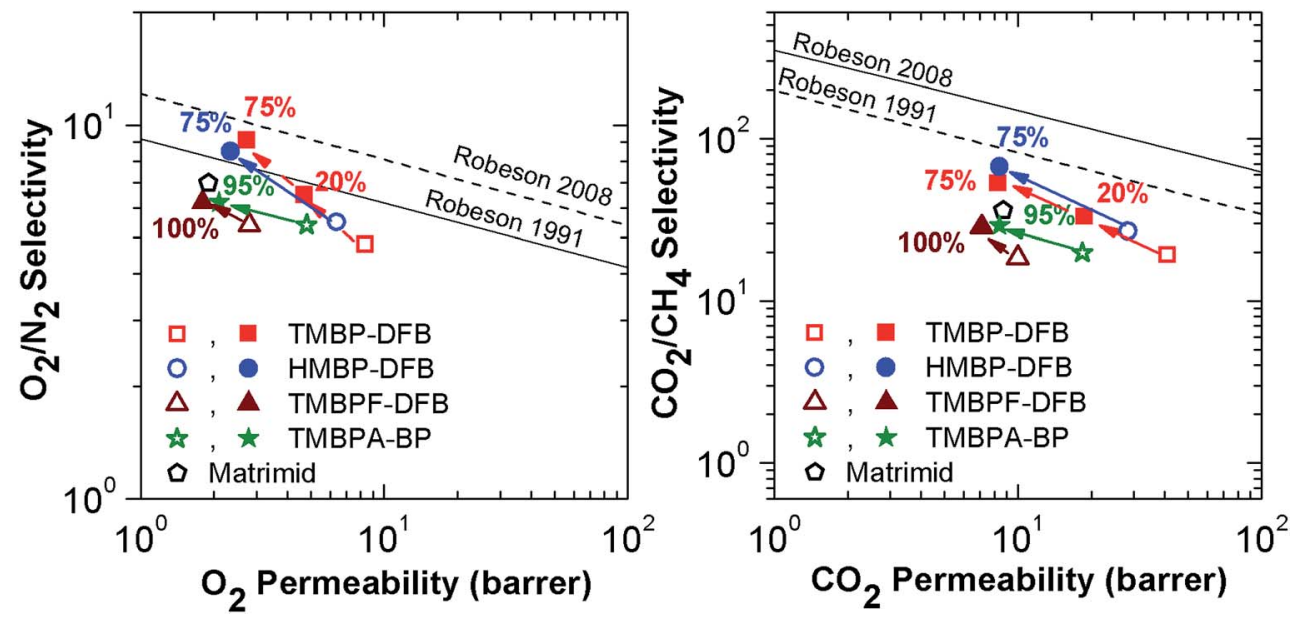

Fig. 11 Upper bound plots for $\mathrm{O}_{2} / \mathrm{N}_{2}$ and $\mathrm{CO}_{2} / \mathrm{CH}_{4}$ gas pairs of TMBP-DFB and HMBP-DFB comparison of linear and crosslinked TMBP-DFB and HMBP-DFB, TMBPF-DFB ${ }^{21}$ (permeability at 10 bar and $35^{\circ} \mathrm{C}$ ) and TMBPA-BP ${ }^{15}$ (permeability at 10 bar and $35^{\circ} \mathrm{C}$ ) and Matrimid ${ }^{33}$ (permeability at 1 bar and $35^{\circ} \mathrm{C}$ ). Open symbols are used for non-irradiated membranes, while solid symbols represent the irradiated ones. The numbers indicate the gel fraction of the membranes. 
for $\mathrm{O}_{2} / \mathrm{N}_{2}$, where a selectivity increase is observed in every case, much higher than for the reference PEEKs, even if the gel fraction was lower. This increase of gas productivity was so high that the UV-irradiated membranes surpassed the 1991 Robeson limit, with TMBP-DFB (75) nearly reaching the $\mathrm{O}_{2} / \mathrm{N}_{2} 2008$ upper bound. This result is outstanding for common glassy polymers.

\section{Conclusions}

The UV-crosslinking of dense membranes of two poly(ether ether ketone)s derived from difluorobenzophenone and bisphenol derivatives, with four or six methyl groups, led to an significant improvement in the gas transport properties. Crosslinking and photooxidation reactions took place during the irradiation process using polychromatic light, with wavelengths above $350 \mathrm{~nm}$, at room temperature and in presence of air. The two polymers were able to produce highly crosslinked membranes, with gel fractions close to $75 \%$ and similar FFV. However, the polymer with higher number of methyl groups on the biphenyl moiety (HMBP-DFB) required half the time to achieve the same gel fraction than the polymer with four methyl groups (TMBP-DFB).

A DFT quantum mechanical study has stated that the higher crosslinking reactivity of HMBP-DFB is not only due to the higher amount of methyl groups, but also to the higher feasibility of formation of methylene radicals in this case.

The gas permeability in both membranes strongly decreased with the irradiation time. In particular the decrease in permeability was much higher for gases with larger size, because the crosslinking enhanced the size-sieving capability. This behavior was reflected in a considerable increase for $\mathrm{O}_{2} / \mathrm{N}_{2}$ and $\mathrm{CO}_{2} / \mathrm{CH}_{4}$ selectivities. In that way, UV irradiation moved the gas transport properties towards Robeson upper bound of 1991, even surpassing this limit for $\mathrm{O}_{2} / \mathrm{N}_{2}$. Moreover, crosslinking is expected to provide a good mechanical integrity to the membrane and is able to counteract the effect of degradation if the irradiation conditions are well controlled.

\section{Conflicts of interest}

There are no conflicts to declare.

\section{Acknowledgements}

We acknowledge the financial support provided by MINECO (MAT2013-45071-R, CTQ2012-31076 and MAT2016-76413-C2R2) and by the National Science Foundation under grant number IIP-1237857. Authors wish to thank Judit González for helping with the characterization of polymers.

\section{References}

1 Y. Yampolskii, Macromolecules, 2012, 45, 3298-3311.

2 R. W. Baker and K. Lokhandwala, Ind. Eng. Chem. Res., 2008, 47, 2109-2121.

3 P. Bernardo, E. Drioli and G. Golemme, Ind. Eng. Chem. Res., 2009, 48, 4638-4663.
4 L. M. Robeson, J. Membr. Sci., 1991, 62, 165-185.

5 L. M. Robeson, J. Membr. Sci., 2008, 320, 390-400.

6 P. Bernardo and G. Clarizia, Chem. Eng. Trans., 2013, 32, 1999-2004.

7 D. F. Sanders, Z. P. Smith, R. Guo, L. M Robeson, J. E McGrath, D. R. Paul and B. D. Freeman, Polymer, 2013, 54, 4729-4761.

8 M. Calle, C. García, A. E. Lozano, J. G. de la Campa, J. de Abajo and C. Álvarez, J. Membr. Sci., 2013, 434, 121-129.

9 B. D. Freeman, Macromolecules, 1999, 32, 375-380.

10 R. A. Hayes, Polyimide gas separation membranes, US Pat. , 4 717 393, 1988.

11 K. Vanherck, G. Koeckelberghs and I. F. J. Vankelecom, Prog. Polym. Sci., 2013, 38, 874-896.

12 C. T. Wright and R. D. Paul, J. Membr. Sci., 1997, 124, 161174.

13 J. McGrath, Y. Chen, R. Guo and B. Freeman, Crosslinked polymer compositions, gas separation membranes of such crosslinked polymer compositions, methods of making such membranes, and methods of separating gases using such membranes, US Pat., 9533254 B2, 2017.

14 J. S. Park, K. L. Gleason, K. E. Gaines, S. J. Mecham, J. E. McGrath and B. D. Freeman, Energy Procedia, 2014, 63, 210-216.

15 J. R. Rowlett, Q. Liu, W. Zhang, J. D Moon, M. E. Dose, J. S. Riffle, B. D. Freeman and J. E. McGrath, J. Mater. Chem. A, 2016, 4, 16047-16051.

16 A. Shaver, J. D. Moon, D. Savacool, W. Zhang, G. Narang, G. Miller, B. Vondrasek, J. J. Lesko, B. D. Freeman, J. S. Riffle and J. E. McGrath, Polymer, 2017, 114, 135-143.

17 B. W. Rowe, B. D. Freeman and R. D. Paul, Polymer, 2009, 50, 5565-5575.

18 A. Bos, I. G. M. Pünt, M. Wessling and H. Strathmann, J. Membr. Sci., 1999, 155, 67-78.

19 M. S. McCaig and D. R. Paul, Polymer, 1999, 40, 7209-7225. 20 Q. Liu, Q. A. T. Shaver, Y. Chen, G. Miller, D. R. Paul, J. S. Riffle, J. E. McGrath and B. D. Freeman, Polymer, 2016, 87, 202-214.

21 B. J. Sundell, A. T. Shaver, Q. Liu, A. Nebipasagil, P. Pisipati, S. J. Mecham, B. D. Freeman and J. E. McGrath, Polymer, 2014, 55, 5623-5634.

22 M. J. S. Dewar, E. G. Zoebisch, E. F. Healy and J. J. P. Stewart, J. Am. Chem. Soc., 1985, 107, 3902-3909.

23 A. D. Becke, J. Chem. Phys., 1993, 98, 5648-5654.

24 C. Lee, W. Yang and R. G. Parr, Phys. Rev. B, 1988, 37, 785789.

25 W. J. Hehre, L. Radom, P. v. R. Schleyer and J. Pople, Ab Initio Molecular Orbital Theory, Wiley, New York, 1986.

26 J. B. Foresman and E. Frisch, Exploring Chemistry with Electronic Structure Methods, Gaussian Inc., Pittsburgh, 1996.

27 H. B. Schlegel, G. E. Scuseria, M. A. Robb, J. R. Cheeseman, G. Scalmani, V. Barone, B. Mennucci, G. A. Petersson, H. Nakatsuji, M. Caricato, X. Li, H. P. Hratchian, A. F. Izmaylov, J. Bloino, G. Zheng, J. L. Sonnenberg, M. Hada, M. Ehara, K. Toyota, R. Fukuda, J. Hasegawa, M. Ishida, T. Nakajima, Y. Honda, O. Kitao, H. Nakai, T. Vreven, J. A. Montgomery Jr, J. E. Peralta, F. Ogliaro, 
M. Bearpark, J. J. Heyd, E. Brothers, K. N. Kudin, V. N. Staroverov, R. Kobayashi, J. Normand, K. Raghavachari, A. Rendell, J. C. Burant, S. S. Iyengar, J. Tomasi, M. Cossi, N. Rega, J. M. Millam, M. Klene, J. E. Knox, J. B. Cross, V. Bakken, C. Adamo, J. Jaramillo, R. Gomperts, R. E. Stratmann, O. Yazyev, A. J. Austin, R. Cammi, C. Pomelli, J. W. Ochterski, R. L. Martin, K. Morokuma, V. G. Zakrzewski, G. A. Voth, P. Salvador, J. J. Dannenberg, S. Dapprich, A. D. Daniels, O. Farkas, J. B. Foresman, J. V. Ortiz, J. Cioslowski, and D. J. Fox, Gaussian 09 (Revision A.1), Gaussian, Inc., Wallingford CT, 2009.

28 R. Dennington, T. Keith and J. Millam, GaussView (Version 5), Semichem Inc., Shawnee Mission, KS, 2009.

29 M. A. Thompson, ArgusLab 4.0.1, Planaria Software LLC, Seattle, WA, 1997-2004.

30 A. E. Lozano, M. L. Jimeno, J. de Abajo and J. G de la Campa, Macromolecules, 1994, 27, 7164-7170.

31 A. Bondi, J. Phys. Chem., 1964, 68, 441-451.

32 HyperChem(TM) Professional (Version 8.0.3), Hypercube, Inc., Florida, USA.

33 M. D. Guiver, G. P. Robertson, Y. Dai, F. Bilodeau, Y. S. Kang, K. J. Lee, J. Y. Jho and J. Won, J. Polym. Sci., Part A: Polym. Chem., 2002, 40, 4193-4204.
34 A.-K. Schuler, O. Prucker and J. Rühe, Macromol. Chem. Phys., 2016, 217, 1457-1466.

35 J. P. Wagner, R. J. Truman, A. E. Puchalski and R. Wake, J. Am. Chem. Soc., 1986, 108, 1127-1138.

36 S. Giancaterina, A. Rossi, A. Rivaton and J. L. Gardette, Polym. Degrad. Stab., 2000, 68, 133-144.

37 I. K. Meier and M. Langsam, J. Polym. Sci., Part A: Polym. Chem., 1993, 31, 83-89.

38 M. Calle, A. E. Lozano, J. de Abajo, J. G. de la Campa and C. Álvarez, J. Membr. Sci., 2010, 365, 145-153.

39 J. L. Santiago-García, C. Álvarez, F. Sánchez and J. G. de la Campa, J. Membr. Sci., 2015, 476, 442-448.

40 C. Álvarez, A. E. Lozano and J. G. de la Campa, J. Membr. Sci., 2016, 501, 191-198.

41 J. R. Wiegand, Z. P. Smith, Q. Liu, C. T. Patterson, B. D. Freeman and R. Guo, J. Mater. Chem. A, 2014, 2, 13309-13320.

42 L. M. Robeson, Q. Liu, B. D. Freeman and D. R. Paul, J. Membr. Sci., 2015, 476, 421-431.

43 L. M. Robeson, A. P. Smith, B. D. Freeman and D. R. Paul, J. Membr. Sci., 2014, 453, 71-83. 